\title{
A GEOGRAFIA COMO CIÊNCIA DAS PRÁTICAS E DOS SABERES ESPACIAIS - POR UM NOVO MODELO CLÁSSICO DE ORGANIZAÇÃO CURRICULAR
}

\author{
Geography as a science of practices and spatial knowledge - towards a new \\ classical model of curriculum organization
}

\section{La geografía como ciencia de las prácticas y de los saberes espaciales - por un nuevo modelo clásico de organización curricular}

\author{
Marcos Antonio Campos Couto \\ Prof. Adjunto do Departamento de Geografia da UERJ-FFP \\ professormarcoscouto@gmail.com
}

Artigo recebido em 28/08/2017 e aceito para publicação em 24/10/2017

DOI: $10.12957 /$ tamoios.2017.30150

\section{RESUMO}

O objetivo é a definição do "clássico" como subsídio aos critérios de montagem de currículos e programas. Fundamental à compreensão da função social da geografia, o artigo apresenta a forma como ao longo da história o discurso e a prática geográfica foram sendo construídos até a sua institucionalização na escola e na universidade. O termo "clássico" não se refere, necessariamente, ao que é tradicional (no sentido negativo do termo), tampouco se opõe ao moderno; mas o que capta questões nucleares do desenvolvimento histórico das sociedades. $\mathrm{O}$ texto apresenta o desenvolvimento das matrizes clássicas do pensamento e da prática geográfica (Tatham, 1959; Moreira, 2014). A partir da definição da geografia como ciência das práticas e dos saberes espaciais e do "clássico" como critério de definição dos conteúdos escolares, propõe novo modelo de organização de programas e currículos.

Palavras-chave: ensino de geografia; currículos e programas; práticas espaciais; textos clássicos.

\section{ABSTRACT}

The goal is the definition of "classic" as input to curriculum and program installation criteria. Fundamental to understanding the social function of geography, the article shows how the speech and geographical practice were built throughout history leading to its institutionalization in school and university. The term "classic" does not refer necessarily to what is traditional (in the negative sense) nor opposes modern; but what captures core issues of the historical development of societies. The text presents the development of the classical matrices of thought and geographical practice (Tatham, 1959, Moreira, 2014). From the definition of geography as a science of practices and spatial knowledge and "classic" as defining criterion of school subjects, proposes new model for the organization of programs and curricula.

Keywords: geography teaching; curricula and programs; spatial practices; classical texts. 
El objetivo es la definición del "clásico" como subsidio a los criterios de montaje de currículos y programas. Fundamental a la comprensión de la función social de la geografía, el artículo presenta la forma como a lo largo de la historia el discurso y la práctica geográfica fueron construidos hasta su institucionalización en la escuela y en la universidad. El término "clásico" no se refiere necesariamente a lo que es tradicional (en el sentido negativo del término), tampoco se opone a lo moderno; Pero lo que capta cuestiones nucleares del desarrollo histórico de las sociedades. El texto presenta el desarrollo de las matrices clásicas del pensamiento y de la práctica geográfica (Tatham, 1959, Moreira, 2014). A partir de la definición de la geografía como ciencia de las prácticas y de los saberes espaciales y del "clásico" como criterio de definición de los contenidos escolares, propone nuevo modelo de organización de programas y currículos.

Palabras clave: enseñanza de geografía; Curriculos y programas; Prácticas espaciales; Textos clásicos.

\title{
INTRODUÇÃO
}

Fundamental à compreensão da função social da geografia, a relação sociedadeeducação é apresentada, neste artigo, na forma como ao longo da história o discurso e a prática geográfica (conhecimento, ciência) foram sendo construídos até a sua institucionalização na escola e na universidade. O objetivo é que a definição do clássico sirva às professoras e aos professores de geografia como subsídio aos seus critérios de montagem de currículos e programas. Consequentemente, o discurso clássico pode servir como instrumento de análise e construção de materiais e livros didáticos, organização de aulas, conteúdos e métodos da prática pedagógica.

Para Dermeval Saviani (2010), clássico...

\begin{abstract}
...é aquilo que resistiu ao tempo, tendo uma validade que extrapola o momento em que foi formulado. Define-se, pois, pelas noções de permanência e referência. Uma vez que, mesmo nascendo em determinadas conjunturas históricas, capta questões nucleares que dizem respeito à própria identidade do homem como um ser que se desenvolve historicamente, o clássico permanece como referência para as gerações seguintes que se empenham em apropriar-se das objetivações humanas produzidas ao longo do tempo. (Saviani: 2010, p. 16)
\end{abstract}

Portanto, o termo "clássico" não se refere, necessariamente, ao que é tradicional (no sentido negativo do termo), tampouco se opõe ao moderno (SAVIANI, 2010, p. 16); mas o que capta questões nucleares - e por isso, permanentes - do desenvolvimento histórico das sociedades.

A questão nuclear e original da geografia, como forma de saber sistematizado, foi a necessidade de organização e estudo do material acumulado, resultante da exploração e compilação de fatos e conhecimentos relativos à superfície terrestre e da elaboração de mapas das áreas que foram se tornando conhecidas e povos conquistados no mundo antigo, incluindo o período dos grandes impérios; dando origem ao que se pode denominar como os primeiros geógrafos ou filósofos-geógrafos: os gregos ${ }^{1}$ (TATHAM, 1959, p. 198).

A partir deste problema original, o texto apresenta o desenvolvimento das matrizes clássicas do pensamento e da prática geográfica, através da geografia científica edificada no período de que vai do final do século XVIII (Tatham, 1959, p. 198) até as 
primeiras décadas do século XX (Moreira, 2008, p. 29); período em que se definiu o âmbito do olhar geográfico, a linguagem, o conteúdo e o método, a epistemologia.

Em seguida, é apresentada a recente proposição de Moreira (2010b, 2017) de definir a geografia como uma ciência das práticas e dos saberes espaciais e, a partir daí, as fases e os conteúdos da construção geográfica das sociedades.

No final, é retomada a questão do clássico como critério de definição dos conteúdos escolares, e suas implicações para a organização de programas e currículos, a partir das proposições expostas neste artigo.

\section{ARQUÉTIPOS, DEFINIÇÕES E ESTRUTURA DO DISCURSO CLÁSSICO}

A geografia matemática, a geografia física, os poucos aspectos humanos e a geografia regional foram estabelecidos pelos gregos, a partir de três necessidades interligadas: "a exploração, que provocou a compilação de fatos relativos à superfície da terra; a elaboração de cartas e mapas das áreas conhecidas; o estudo do material arrecadado" (Tatham: 1959, p. 198). Dos gregos, este autor destaca Strabo (Estrabão, séc. I) e Cláudio Ptolomeu de Alexandria (séc. II).

De acordo com Moreira (2014, p. 14), com Estrabão nasce o modelo da descrição da paisagem, "uma forma de olhar que flagra o mundo no modo como este é visto através da imensa diversidade de paisagens que expressam a multiplicidade de modos de vida dos homens na superfície da Terra". Segundo Tatham (1959, p. 199), para Estrabão a geografia "nos familiariza com os habitantes da terra e do mar, com a vegetação, frutas e peculiaridades dos vários pontos da terra, tornando aquêles que a cultivam homens que levam a sério os grandes problemas da vida e da felicidade". Com Ptolomeu nasce o modelo do registro cartográfico e da cosmografia. Embora também descreva a paisagem, seu foco é a Terra no universo, seu modelo "é uma forma de olhar que flagra esse mesmo mundo, mas no modo como o todo do universo verticalmente se projeta em paisagens na superfície do planeta, as paisagens expressando em sua diversidade de formas a complexidade cósmica das relações da Terra com o universo" (Moreira: 2014, p. 14). Para Estrabão, a corografia terrestre é o tema da Geografia, pois seu foco é a superfície terrestre, a descrição direta da paisagem. Para Ptolomeu, a descrição da paisagem está inserida no conhecimento da reciprocidade da relação da Terra e do Cosmos, necessário ao entendimento da Terra desde sua condição de planeta e centro do sistema (seu pensamento é aristotélico-geocêntrico), sendo a cosmografia o conhecimento que engloba a Geografia. A prática geográfica é a da descrição, inventário e classificação de informações sobre os povos e seus territórios a partir da observação de suas paisagens (Estrabão), do relato de viajantes e mercadores e do registro cartográfico (Ptolomeu).

De acordo com Yves Lacoste (2010), esta geografia corresponde à relação entre práticas e representações espaciais dos chefes de guerra, dos príncipes, do imperador, momento em que se tornou necessário representar outros espaços (em diferentes escalas), territórios dominados ou a dominar, exigente da produção de conhecimentos sobre estradas, distâncias, regiões distintas: "O imperador deve ter uma representação global e precisa do império, de suas estruturas espaciais internas (províncias) e dos Estados que o contornam" (LACOSTE, 2010, p. 42). Esta geografia é um "conjunto de representações cartográficas e de conhecimentos bem variados, visto em sua relação com o espaço terrestre" (LACOSTE, 2010, p. 26).

Bernhard Varenius (1622-1650) recupera esses arquétipos fundadores de Estrabão e Ptolomeu (Moreira, 2014), entretanto incluindo-os na nova teoria do universo do século XVII. Impactado pela interpretação matemático-quantitativa do 
universo de Copérnico, Kepler e Galileu, a geografia, que ele divide em geral ou universal e especial, é um ramo da matemática. De acordo com Tatham (1959, p. 201), na Geographia Generalis de Varenius a geografia geral (ou sistemática) compunha-se de três partes: Absoluta, parte terrestre (a Terra como um todo, forma, tamanho, etc.); Relativa ou planetária (relação da Terra com outras estrelas) e Comparativa (descrição geral da Terra, relativa localização dos lugares na superfície, princípios de navegação). A geografia especial, livro que não foi concluído, era dividida em: propriedades da astronomia (inclusive o clima), propriedades terrestres (descrição do relevo, vegetação e a vida animal nos diversos países) e propriedades humanas (descrição dos habitantes, comércio e governo dos países). De acordo com Hartshorne (1978, p. 115, 116), caberia à geografia geral de Varenius o estudo da "Terra em geral, descrevendo suas várias divisões e os fenômenos que a afetam como um todo"; fornecedora das "leis gerais" que seriam "aplicadas nos estudos de países particulares", conteúdo da geografia especial.

Varenius atualiza as ideias de Estrabão e Ptolomeu para a cosmologia heliocêntrica:

\begin{abstract}
Varenius atualiza essa teorização ptolomaica nos termos da Astronomia heliocêntrica de Copérnico e da teoria físico-espacial dos movimentos corpóreos de Newton e Descartes. E atualiza igualmente a leitura horizontal da Geographia de Estrabão, trazendo-a também para sua contemporaneidade, incorporando de um lado o novo mundo vindo das grandes navegações e descobertas, já antes cartograficamente representado no Planisfério de Gerhard Kremer Mercator, em 1569, e de outro a nova percepção do espaçotempo advinda dos conhecimentos criados pela viagem de circum-navegação de Fernão de Magalhães. (MOREIRA: 2014, p. 15)
\end{abstract}

Portanto, não apenas incorpora os modelos fundadores, mas o faz à luz da nova base cartesiano-newtoniana das ideias de espaço, de tempo e de geografia. Moreira (2014, p. 59) afirma que Varenius, embora morto precocemente, foi o geógrafo da transição da geografia antiga para a geografia moderna. Seu pensamento atravessa os séculos XVIII, XIX e XX, sendo incorporado na institucionalização da geografia na Universidade como disciplina acadêmica, nos currículos como disciplina escolar e nos livros didáticos ${ }^{2}$.

Varenius vive o momento de transição das filosofias naturais dos gregos, com destaque para o confronto entre a física qualitativa e a cosmologia de Aristóteles e a idéia platônica de que o mundo (a física ${ }^{3}$ ) se organiza segundo o padrão matemáticogeométrico; em direção aos novos paradigmas da ciência moderna e que dará origem às ciências naturais e à separação, na física do mundo, entre o que é inorgânico e orgânico ${ }^{4}$, desembocando na questão ontológica do ser humano como ente da natureza contraposta com a ideia da natureza independente e dominada pelo homem.

Nesta transição, mas já na segunda metade do século XVIII, Tatham (1959) destaca dois autores alemães: Forster e Kant. O primeiro mais prático porque interessado e em contato com a realidade diversa do planeta terra, vai desenvolver um método científico para tratar dos dados observados. Kant se interessou pela geografia em sua pesquisa filosófica sobre o papel da razão e dos sentidos na construção do conhecimento. Embora na primeira metade do século XVIII não tenha havido muitos progressos na geografia científica, Tatham (ibidem, p. 203) indica a polêmica entre a escola político-estatística de descrições regionais das unidades políticas, e a geografia pura que propunha estabelecer as fronteiras naturais a partir dos contornos do relevo ou das bacias hidrográficas.

Os Forstes (pai e filho) deram contribuições para o que vai se consagrar, na virada do século XIX para o século XX, como geografia humana e geografia regional. A 
observação detalhada de diversas partes da terra permitiu a J.R Forster (1729-1798) colecionar fatos, compará-los, classificá-los e extrair generalidades que conduzissem à explicação das causas dos fenômenos; muito próximo dos passos do que naquele momento vinha se constituindo como o método experimental. Com este "cuidadoso método científico", afirma Tatham (1959, p. 204), reconheceu o problema da relação do homem com o meio e fez descrições sobre povoamento, densidade da população e mobilidade dos povos. Seu filho, J. G. Forster (1754-1794), amigo de Alexander Von Humboldt, seguiu o método de observação do pai, desenvolvendo a metodologia de observação da paisagem e da descrição regional.

Ao investigar o conhecimento, suas possibilidades, limites e esferas de aplicação, o filósofo iluminista prussiano Immanuel Kant (1724-1804) estabelece a distinção entre conhecimento puro e empírico. Todo conhecimento começa com a experiência, através dos objetos que tocam os sentidos e produzem representações. Pela sensibilidade - um dos troncos do conhecimento - os objetos são dados ao homem. Entretanto, nem todo conhecimento é originado da experiência e das impressões dos sentidos: são os conhecimentos puros, através dos quais os objetos são pensados; o que corresponde ao tronco do entendimento que produz conceitos. Também chamados de conhecimentos a priori, pois anterior e independente de toda a experiência. Os conhecimentos empíricos são possíveis apenas a posteriori, isto é, com a experiência.

De acordo com Tatham (1959, p. 205), para Kant", as fontes do "conhecimento empírico do homem com relação ao mundo" são as "percepções sensoriais subjetivas" e as "percepções sensoriais objetivas". Para as primeiras, o mundo é o próprio "eu" do homem, sua alma; enquanto para as percepções objetivas, o mundo é a natureza. Assim, para Kant, a antropologia (atual psicologia) estuda a alma do homem, enquanto a geografia física ${ }^{6}$ estuda a natureza; sendo esta última a primeira parte, essencial e preliminar, do conhecimento do mundo e da compreensão das percepções. Para que a experiência não seja uma coleção de impressões desordenadas da natureza, a geografia física fornece a concepção de um todo sistemático, uma ideia de conjunto. Tatham (1959, p. 206) afirma ainda que Kant classifica o conhecimento empírico "de acordo com um conceito" ou de acordo "com a distribuição no tempo e no espaço". A primeira fornece uma classificação racional, um sistema da natureza, como a classificação dos seres vivos de Lineu, do domínio, reino até a espécie; enquanto "a que se relaciona com o tempo e o espaço é uma classificação física" e fornece "uma descrição geográfica da natureza". Assim, a história e a geografia são descrições da natureza, sendo a história o "registro dos acontecimentos que se sucedem no tempo" e a geografia "é o relatório de fenômenos que se sucedem no espaço"; ambas representando o "todo de nossa percepção". Sensibilidade (sensação, percepção, intuição) e Entendimento (conceito) são os troncos do conhecimento humano. Espaço e tempo, então, são duas formas puras da intuição sensível (sensibilidade), a partir dos quais a multiplicidade de fenômenos é intuída em certas relações, permitindo aos seres humanos organizar suas percepções sensórias objetivas.

Desta forma, conclui Tatham, os Forsters demonstraram o método de pesquisa, e Kant definiu a geografia e seu ramo de investigação; dois alicerces sobre os quais o edifício da geografia científica vai se erguer no século XIX.

Já presente no pensamento de Kant, o eixo das preocupações do geógrafo e, consequentemente, da própria ideia de geografia, passa a ser, no século XIX, a questão da relação homem-meio. A sociedade europeia vive a transição para a modernidade industrial:

Homem e meio formam, assim, o conteúdo e a substância da teoria geográfica que em ambos surge, uma teoria correspondente ao espírito da época em sua busca da compreensão e mapeamento da diversidade 
geográfica de um mundo ampliado, ao tempo que do conhecimento analítico de uma superfície terrestre que desde o século XVI é domínio europeu, mas que este tem nesse momento dos séculos XVIII e XIX que organizar de um modo novo, fruto da demanda de uma sociedade europeia agora construída no parâmetro técnico e de mercado da Revolução Industrial, não mais lhe satisfazendo apenas descrever e mapear, mas ocupar economicamente. (Moreira: 2014, p. 16)

Ou seja, trata-se da transição das mudanças de demanda do período dos impérios coloniais e do mercantilismo, para as novas necessidades da sociedade urbanoindustrial, com todas as implicações quanto ao papel das ciências em geral e da geografia em particular.

O iluminismo kantiano, o espiritualismo cristão e a filosofia da natureza do romantismo na Alemanha (Tatham: 1959; Moreira: 2008, 2014) chegam aos alemães Karl Ritter (1779-1859) e Alexander von Humboldt (1769-1859), fundadores da geografia universitária alemã, para os quais o "tema é o mundo (natural-humano) do homem e não se pensa homem e natureza em dissociado, porque para ambos a referência da geografia é a superfície terrestre e o homem o ser que vive na superfície terrestre" (MOREIRA: 2008, p. 24). Na Alemanha a questão da relação homem-meio e do surgimento de gerações de geógrafos, é o problema da extrema fragmentação e dos critérios de unificação dos territórios num único Estado-nação.

Ritter se interessou pela geografia na escola em que freqüentou pois, baseada na pedagogia renovadora de Rousseau e Pestalozzi, propunha despertar o entusiasmo pela natureza através de acuradas observações realizadas em trabalhos de campo. Por isso Ritter se utilizava do estudo das relações espaciais, ainda hoje muito presente na geografia de $1^{\circ}$ ao $5^{\circ}$ anos, que estabelecia "a relação das coisas com a vizinhança imediata: a escola, depois, o pátio da escola, em seguida a região do lar, os limites da área iam-se gradativamente expandindo até abarcar o mundo inteiro" (Tatham, 1959, p. 208). Tatham reproduz o objetivo de Ritter, retirada do prefácio de sua primeira publicação de 1804, que indica a sua idéia do que seja a geografia:

\footnotetext{
Apresentar um quadro vivo do conjunto da terra, seus produtos naturais e cultivados, seus aspectos naturais e humanos, e demonstrá-los como um todo coerente, de tal forma que a mais significativa conclusão sobre o homem e a natureza ficarão evidentes, principalmente quando comparados lado a lado. (Tatham, 1959, p. 208 e $209^{7}$ )
}

Utilizando o método empírico-comparativo de Forster e o aperfeiçoando, Ritter centraliza a geografia no homem, embora no contexto da unidade homem-natureza da filosofia romântica. O objetivo é familiarizar o homem "com o cenário de suas atividades"; entretanto, não para descrevê-lo, mas para compreender a sua relação com o homem. A denominada por Ritter geografia comparativa geral foi aplicada ao estudo das regiões e ao conceito de individualidade regional, tornando a tarefa da ciência geográfica a de pesquisar e apresentar tais individualidades da terra.

Alexander Von Humboldt (1769-1859), de família rica, ganhou fama pelas suas viagens $^{8}$, que lhe permitiram fazer muitas observações e descrições detalhadas de diversos fenômenos, desde temperaturas, solos, natureza das rochas, tipos de plantas até aspectos humanos; e desenvolver estudos de botânica, geologia, física, química, anatomia, fisiologia, história e vários aspectos da geografia. De acordo com Tatham (ibidem, p. 214), as tentativas "para coordenar todas estas observações dos fenômenos naturais levaram Humboldt à geografia". Diferente da catalogação e classificação dos seres orgânicos segundo analogias de suas estruturas internas (sistemas da natureza), à 
ciência da distribuição espacial cabe apresentá-los segundo sua distribuição por todo o planeta, segundo as altitudes, latitudes, zonas de habitação, etc. Embora compartilhando com Ritter o conceito de unidade viva da natureza de Spinoza, de uma causalidade inerente, Humboldt não era antropocêntrico e teleológico (unidade ordenada por Deus para o desenvolvimento do homem), mas panteísta, idéia de que Deus não existe como espírito separado, mas como a mesma e única unidade do universo. Cabe à geografia demonstrar esta unidade da natureza, isto é, a pesquisa da unidade das relações da vida orgânica - incluindo o homem - com a inorgânica superfície da terra. Humboldt se vale do método empírico de pesquisa e descrição da paisagem, de cuidadosa observação, comparação e crítica dos fatos, propostos pelos Forsters, e que envolve a generalização de fatos particulares, o reconhecimento de leis empíricas, a descoberta de conexões causais. Utilizando da representação gráfica dos dados, das cartas geográficas, o âmbito da sua geografia foi, sobretudo, o dos estudos sistemáticos.

A partir de Kant, mas sobretudo com Ritter e Humboldt, a geografia vai se institucionalizar na universidade, que passa a assumir grande protagonismo na definição de seu lugar, papel e formato; sem deixar de ser obra de pensadores ou das sociedades científicas que já atuam desde o século XVI (Moreira, 2014, p. 81, 82). Surge, então, a geografia dos professores (LACOSTE, 2010), cujo papel foi o de criar a identidade do povo com o seu estado-nação, na forma do nacionalismo patriótico, papel que não cabia apenas à geografia, mas à escola e ao sistema escolar como um todo.

O idealismo da filosofia romântica de Ritter e Humboldt entra em crise com a crítica do materialismo, que exerce forte influência sobre a filosofia da ciência na segunda metade do século XIX. A ênfase idealista da unidade da natureza será substituída pelos estudos sistemáticos, altamente especializados, "e levados a efeito por cientistas [como Oscar Peschel (1826-1875)] que tendiam em ser primeiro geomorfologistas e climatologistas, e geógrafos apenas em segundo lugar” (Tatham, 1959, p. 221).

O darwinismo e os novos parâmetros científicos do positivismo, construídos a partir da filosofia do naturalismo mecanicista, estão na origem de outra fase de desenvolvimento da geografia moderna: a modernidade industrial e a geografia fragmentária dos séculos XIX e XX (Moreira, 2008). Por isso, então, que no final do século XIX, a tensão entre uma geografia holista da relação homem-meio, por um lado, e a fragmentação e pulverização do pensamento geográfico em diferentes geografias sistemáticas $^{9}$, por outro, vai impactar o pensamento de nova geração de geógrafos, e levar a uma nova definição de geografia, já no século XX: o estudo da organização do espaço pelo homem.

Depois da morte de Ritter e Humboldt em 1859 e com a crítica materialista, o desenvolvimento dos estudos sistemáticos e as divisões entre geografia física e geografia histórico-política, estudos sistemáticos e geografia regional, conduziram ao dualismo entre a geografia física sistemática e a geografia humana regional.

Friedrich Ratzel (1844-1904), com seu livro Geografia Humana (Anthropogeographie) de 1882, investigou os "aspectos da superfície da terra que estão relacionados com o homem dentro dos moldes sistemáticos" (Tatham, 1959, p. 222). Preocupado com a distribuição do homem sobre a terra condicionada pelas forças naturais, também buscou aplicar, seguindo Ritter, a inter-relação dos fenômenos da superfície da geografia comparativa e a ideia do mundo como um todo integral. Entretanto, distinto de Ritter, sua geografia humana era sistemática e não regional, e a partir da idéia de evolução de Charles Darwin (1809-1882): 
Ratzel via o homem como o produto final da evolução, uma evolução cuja principal conseqüência era a seleção natural dos tipos na conformidade da capacidade de ajustarem-se ao meio físico. Assim, enquanto Ritter escrevera sobre a relação recíproca do homem e da natureza, relação esta que era parte de um todo harmonioso, servindo às finalidades criadoras de Deus, Ratzel tendia a ver o homem como o produto de seu meio, moldado pelas fôrças físicas que o cercavam e somente vencendo quando adequadamente adaptado à exigência das mesmas; a finalidade última de tal adaptação, se houver, está fora da laçada de suas pesquisas. Dessa forma, há um matiz determinista na maioria das obras escritas por ele. (Tatham, 1959, p. 223)

Do retorno à Ritter, Ratzel avalia que é necessário destacar, na investigação comparativa, as relações entre o estado e a superfície terrestre, ou seja, a geografia política. Combinada com a influência da biologia evolucionista adota "a teoria orgânica do estado e sociedade, isto é, o conceito de estado como um organismo parte humano e parte terrestre" (Tatham, 1959, p. 223), no livro Geografia Política de 1897:

\begin{abstract}
Os estados são considerados em todas as fases de sua evolução como organismos, cujo aspecto geográfico reside na sua necessária relação com o solo. Nesse solo evoluem, como demonstram a história e a etnografia, enquanto cada vez mais se aprofundam em seus recursos. Dêste modo, parecem formas limitadas em áreas e nelas localizadas no círculo de fenômenos que podem ser geogràficamente descritos medidos, mapeados, ou comparados. (Ratzel, apud Tatham, 1959, p. 223)
\end{abstract}

Tatham inclui comentário da geógrafa americana Ellen Churchill Semple (18631932) afirmando que a teoria orgânica do estado de Ratzel foi marcada pela grande influência, em sua época, do filósofo inglês Herbert Spencer (1820-1903), que aplicou à sociologia e a todos os níveis da atividade humana, ideias que retirou das leis da evolução, em particular a tese de sobrevivência do mais apto. Semple afirma que a retirada da teoria orgânica do estado da obra de Ratzel e, em particular, do livro Geografia Política, não compromete a qualidade do conjunto, a análise das "relações entre o desenvolvimento e o caráter das unidades políticas e sua posição na superfície da terra, tamanho, fronteiras, relação com o mar, etc., ... todas sistemática e crìticamente investigadas" (Tatham, 1959, p. 224).

Ao reafirmar o lugar do homem, Ratzel corrigiu a tendência, presente na segunda metade do século XIX, de superestimar os aspectos físicos da geografia, restabelecendo certo equilíbrio; embora priorizando a abordagem sistemática em detrimento da geografia regional.

A partir da sugestão do geógrafo alemão Ferdinand Von Richthofen (1833-1905) de restabelecer a relação entre os estudos regionais e sistemáticos, Alfred Hettner (1859-1941) reviveu os estudos de Kant sobre a geografia (neo-kantismo), incluindo os estudos sistemáticos de Humboldt, Peschel e Ratzel e os estudos regionais de Ritter, Marthe e Richthofen, na perspectiva de transposição do dualismo da geografia.

Acrescente-se o combate dos intelectuais da sociologia francesa (Durkheim, Marcel Mauss, Simiand) contra a antropogeografia e a geografia política de F. Ratzel (LACOSTE, 2010, p. 115 a 119; MOREIRA: 2009, p. 21 a 30), desenvolvido na virada do século XIX para o XX. Os sociólogos o acusam de fazer mais política ${ }^{10}$ do que ciência; afirmam sua ambição de querer abranger tudo o que há sobre a superfície da terra na medida em que Ratzel propõe estudar a relação entre o Estado e o solo, englobando temas que seriam supostamente da alçada dos sociólogos, de sua ciência especial denominada morfologia social. Esta polêmica se desdobra em vários episódios, como a palestra realizada por La Blache em 1913 em que afirma que a geografia é 
ciência dos lugares e não ciência dos homens (LA BLACHE, 1985, p. 47), frase interpretada por Lucien Febvre ${ }^{11}$ como sendo o foco da geografia o solo e não o estado. Esta frase de La Blache é reproduzida três vezes no livro deste importante historiador Lucien Febvre ${ }^{12}(1954$, p. 463, 464) que afirma que a geografia deva ser uma "ciência modesta" e estudar apenas o solo, e não o Estado ${ }^{13}$ e o solo como propunha F. Ratzel ${ }^{14}$ (LACOSTE, 2010, p. 117).

De acordo com Moreira (2008, p. 19 e 20), todos esses embates entre sociólogos e geógrafos, e da concepção positivista de ciência e à sua perspectiva de fragmentação da geografia com o movimento neo-kantiano, desembocam na consolidação e ampliação das geografias sistemáticas e na criação da geografia humana (Ratzel, Brunhes), da geografia física (De Martonne), da geografia regional (Hettner, La Blache) e da geografia da civilização (Ratzel, Reclus e La Blache, Marsh, Sauer). As controvérsias dos positivistas e com os neo-kantianos, ou seja, entre geógrafos sistemáticos, geógrafos físicos e humanos, está na base da constituição da estrutura NH-E (natureza-homem-economia), estabelecida pelo geomorfólogo-geógrafo francês, discípulo de Paul Vidal de La Blache, Emannuel De Martonne (Moreira, 2014, p. 48).

É neste contexto - início do século XX - que se cria a geografia universitária no Brasil, já na década de 1930 e também o IBGE (1937/38). De acordo com Moreira (2010, p. 11), o pensamento geográfico brasileiro fundado na universidade e no IBGE resulta de quatro influências: a francesa de La Blache, a franco-germânica de Brunhes, a germânica de Hettner e a norte-americana de Sauer e Richard Hartshorne (1899-1992); trazidos para o Brasil por Pierre Monbeig (1908-1987) e Francis Ruellan (1894-1975), Pierre Deffontaines (1894-1978), Leo Heinrich Waibel (1888-1951).

Entretanto, é importante ressalvar que no século XIX já há a presença destes formatos do discurso e da prática geográficos em livros didáticos e currículos destinados a geografia escolar.

No desenvolvimento das matrizes clássicas do pensamento e da prática geográfica, e na consequente organização de formatos de pesquisa e de ensino, resumidos acima, a fragmentação neokantiana e positivista exerceu maior influência. A partir daí Moreira $(1987,2014)$ indica um rol de problemas, ao mesmo tempo em que propõe a revisão crítica do pensamento buscando reaver os elos e tentativas de contrapontos ao discurso fragmentário.

O núcleo central de todos os problemas é o conceito de homem e, consequentemente de natureza, como reciprocamente excludentes. O homem atópico é aquele que não pertence à natureza e nem à história real das relações de classe, na qual o seu caráter de sujeito da história é tornado obscuro. Ora ele é população, ora habitante, ora trabalho, ora ação antrópica com suas necessidades. $\mathrm{O}$ outro lado desta noção de homem demográfico-antropológico-econômico é o conceito de natureza como sendo algo mecânico e externo ao homem, o conjunto dos seres inorgânicos, a naturezarecursos.

Quanto aos percalços da prática e da teoria geográficas, a tensão entre visões holistas, por um lado, e fragmentárias e integradoras, de outro, desemboca numa ciência de quase tudo e de nada precisamente delimitado (a questão sujeito-objeto), de forma sem conteúdo ou do conteúdo sem forma, do real, mas aparente, de relação, mas dicotômica, e de ambiguidade discursiva, tornando, por exemplo, a paisagem como uma categoria da geografia física e o espaço, da geografia humana.

Estes formatos se reproduzem durante todo o século XX. A partir dos anos 1950, alguns movimentos de renovação se desenvolvem: a nova geografia ${ }^{15}$ nos EUA, a geografia ativa ${ }^{16}$ na França e o conceito de geossistema a partir da geografia aplicada soviética ${ }^{17}$. Entretanto, seus problemas permanecem em grande parte, apesar do 
processo de renovação crítica da geografia no mundo e no Brasil que atravessa o século XX e penetra no século XXI, chegando até os dias de hoje.

Em seguida se apresenta um esforço de superação destes impasses, que articula reflexões recentes à retomada de esforços pretéritos de pensar a teoria, o método e novos formatos de organização da pesquisa e do ensino de geografia.

\section{GEOGRAFIA: UMA CIÊNCIA DAS PRÁTICAS E DOS SABERES ESPACIAIS}

Já foi proposto à metodologia do ensino (Couto, 2011) o movimento que vai das práticas e saberes espaciais ao processo de construção de conceitos geográficos (a geografia como ciência). Aqui, o que se apresenta é o movimento contrário, isto é, a compreensão da geografia como ciência das práticas e dos saberes espaciais, com o propósito de definir um formato de pesquisa e, sobretudo, de ensino de geografia - um novo discurso clássico.

Antes e hoje, em certo sentido, independentemente da existência dos livros (de Estrabão, Ptolomeu, etc) ou de sua institucionalização nas sociedades científicas, nas universidades e escolas (nos currículos), a geografia é um saber da prática social. Para Hartshorne (1978, p. 16) o alicerce desse interesse e saber popular foi a descoberta, pelo homem, de que seu mundo variava de lugar a lugar e da curiosidade acerca dos outros lugares. Assim, por fazer parte do cotidiano, a geografia é uma forma de saber que goza de muita popularidade, decorrente da presença dos mapas, do contato com as paisagens, e das práticas espaciais, isto é, do "fato de que todo dia fazemos nosso percurso geográfico, de casa para o trabalho, do trabalho para a escola, da escola para o trabalho, pondo a geografia na própria intimidade das nossas condições de existência" (MOREIRA: 2010b, p. 45). As práticas espaciais se inscrevem na relação homem-meio e na luta pela sobrevivência. A continuidade - e acúmulo dos produtos - das práticas espaciais "vai levando o homem a distinguir os melhores locais" para o cultivo e criação para prover-se cada vez melhor dos meios de sobrevivência. Esse processo envolve experimentações, sistematização de experiências, comparações, abstrações, transformações das práticas, ou seja, um conjunto de saberes sociais/espaciais que tornam as práticas espaciais mais eficientes e abrangentes. Incorporando novas áreas e aumentando a escala de sistematização do conhecimento empírico, os saberes ganham "níveis crescentes de universalidade cuja consequência é a transformação dos saberes na ciência geográfica" (MOREIRA: 2010b, p. 46). Daí o autor denominar a geografia como uma ciência das práticas e saberes espaciais (2017).

Esta transformação das práticas em saberes e em ciência tem o mesmo significado da passagem da percepção e do saber do espaço vivido, ao discurso teórico do conceito. Neste processo, a percepção expressa diferentes escalas geográficas, na medida em que o espaço vivido é percebido como uma combinação de lugares (residência, escola, local de trabalho, etc), que são articulados em redes; cuja conseqüência pode ser a transformação da percepção das coisas singulares, em explicação da estrutura de suas relações universais (e vice-versa). Assim, afirma o autor:

...podemos dizer que a geografia é um discurso teórico universal que combina a escala mais simples das coisas singulares da percepção à mais abstrata e complexa da totalidade do conceito, embutindo em sua estrutura desde as práticas espaciais e seus saberes até o pensamento abstrato que é o domínio da ciência. (Moreira, 2010b, p. 48)

Isto significa viver, ver, perceber e pensar o espaço de modo integrado. Entretanto, a percepção, o saber e a ciência, como tudo que diz respeito aos seres 
humanos, também são campos de disputa ideológica; colocando o difícil problema da relação entre ideologia e ciência. Ambas se valem do real-aparente, de sua percepção e descrição, para construir os seus discursos, exigindo a distinção entre aparência e essência do mundo, entre espaço vivido e percebido e a essência da organização espacial da humanidade; sobretudo na sociedade capitalista, em que seu caráter de classe se reproduz em todos os campos da experiência humana.

A construção geográfica da sociedade resulta, então, das práticas e saberes espaciais. Os saberes vêm das práticas ao tempo que as orientam. Desse amálgama surge a sociedade geograficamente construída. As práticas e os saberes espaciais comandam as relações de interação da sociedade e seu espaço em cada contexto de história.

Lacoste (2010) vê nesta relação entre práticas espaciais e suas representações (mapas, conceitos), o que explica o grande interesse pelos fenômenos geográficos dos estados-maiores militares e das corporações financeiras. As diversas representações de espaço ligadas ao conjunto das práticas sociais se relacionam à importância estratégica e econômica dos fenômenos de localização. Das mudanças que ocorreram ao longo da história nas práticas sociais em relação ao espaço, Lacoste vai definindo e caracterizando as práticas espaciais. Da leitura de seu texto, pode-se resumir que as práticas espaciais são práticas sociais de: localização e de reconhecimento de pontos de referência; deslocamentos e fenômenos que conformam um determinado conjunto espacial com configuração e limites próprios; conquista e domínio de territórios; representação dos espaços em diferentes escalas; delimitação de espaços e interligação entre eles; entrecruzamento de diferentes conjuntos espaciais.

Práticas espaciais são ações que têm por base e âmbito a tríade localizaçãodistribuição-arranjo espacial (MOREIRA, 2017). Para o autor:

\begin{abstract}
A bússula que dirige o modo de arranjo espacial efetivo que o binômio localização-distribuição aqui e ali instala em sua pertinência de sincronia e diacronia com os resultados pretendidos da geograficidade - o ser-estar espacial do homem - almejada pela intervenção humana. Colada ao dia-dia da práticas espaciais como categorias do empírico geográfico, é a percepção que sinaliza à sociedade para o papel necessário de uma teoria de espaço em seu processo constitutivo de construção geográfica. (Moreira, 2017, p. 40)
\end{abstract}

Portanto, como saber ou como ciência, o discurso e a prática geográficos se desenvolvem através das noções e dos conceitos, das categorias do empírico geográfico e das categorias teóricas da paisagem, do território e do espaço. As práticas e saberes espaciais constituem as fontes seminais "do nível empírico-cotidiano do senso comum do plano da prática-saber do mundo vivido", mas também "do nível abstrato-concreto da universalidade científica do plano da prática-saber do discurso formal-científico" (ibidem, p. 28).

\title{
AS FASES E OS CONTEÚdOS DA CONSTRUÇÃO GEOGRÁFICA DA SOCIEDADE
}

Saberes, categorias empíricas e conceitos geográficos, são abstrações que expressam (e constroem) a práxis espacial, sua percepção, descrição e/ou interpretação. Estas abstrações se movimentam entre um polo mais prático - o da prática e da percepção espacial - e outro mais teórico - o da interpretação da constituição geográfica das sociedades no seu todo dinâmico-estrutural. 
Como síntese de múltiplas determinações de todas as práticas espaciais, a dinâmica geográfica é visualizada pelos conceitos mais teóricos. No movimento entre a paisagem, o território e o espaço, propõe-se tornar o mundo em concreto-pensado. Inspirado em Pierre George (Os métodos da geografia), Moreira (2007) propõe o caminho que vai do visível ao invisível, e do invisível ao visível. No primeiro caso, parte-se da indagação dos arranjos da paisagem, passando por sua análise em termos de recortes de domínio (territórios), para chegar ao espaço enquanto conteúdo de organização da sociedade. No caminho inverso, parte-se do conteúdo mais profundo e estrutural da (re)produção do espaço até retornar à paisagem como uma rica totalidade de determinações e relações diversas.

Pelas categorias empíricas se reconstitui o processo - fases e conteúdos - de construção geográfica da sociedade. Moreira (2017) distingue três fases deste processo de produção do espaço geográfico e, para cada uma, seu conjunto de categorias empíricas das práticas espaciais (QUADRO I):

\begin{tabular}{cc} 
Fases & $\begin{array}{c}\text { QUADRO I } \\
\text { Categorias empíricas }\end{array}$ \\
\hline Montagem & A seletividade \\
\hline A unodiversidade \\
A unicidade \\
A tecnificação \\
A territorialização \\
A politização \\
A regulação \\
A mobilidade \\
A urbanização \\
A compressão \\
A fluidificação \\
A sociodensificação \\
\hline Reestruturação & Por agregação de arranjos, de prática a prática, \\
& a armadura ganha peso e escala. Até a \\
& sociodensificação esgotar a capacidade do \\
& arranjo assimilar relaçõe novas. O ciclo se \\
& fecha. E um novo ciclo construtivo se abre, com \\
& a reestruturação que recria e refaz o poder \\
integrativo do arranjo. É o tempo de uma \\
relação sociedade-espaço nova.
\end{tabular}

A apresentação destas três fases de organização geográfica das sociedades é feita, a seguir, em dois subtítulos. Em primeiro lugar, as fases da montagem e do desenvolvimento. Em seguida, a fase da reestruturação.

\section{AS PRIMEIRAS LOCALIZAÇÕES E A CONSTITUIÇÃO DO HABITAT}

A fase da montagem corresponde às primeiras localizações; a fase do desenvolvimento é o da estruturação do arranjo espacial a partir da constituição do habitat, pelo qual a sociedade se organiza geograficamente; e a fase da reestruturação corresponde à entrada num novo ciclo de construção do espaço.

Princípio de localização geográfica, a seletividade é a escolha do local de fixação espacial das ações com as quais a sociedade vai construir o seu habitat. Através 
de experimentações ${ }^{18}$ - "ensaio e erro" -, a seletividade vai permitindo ou construindo a ambientação, a territorialização e o enraizamento cultural da humanidade.

A diversidade cultural e ambiental do planeta faz do processo de seletividade uma tensão permanente entre unidade e diversidade, transformando a localização seletiva em uma distribuição múltipla e, consequentemente, o habitat em um arranjo espacial plural: "Esse todo sistêmico de distribuição múltipla de localizações seletivamente escolhidas converte-se numa configuração de extensão progressivamente ampla de possibilidades de vida socialmente criadas" (MOREIRA, 2017, p. 30). Tanto prática quanto simbólica, a unicidade constitui "A unidade do símbolo cultural dos gêneros de vida e a unidade metabólica do trabalho. Uma e outra retransfigurada na forma própria de unidade estrutural e orgânica do espaço de cada comunidade" (MOREIRA: 2017, p. 31). Do ponto de vista simbólico, a unidade pode ser construída a partir de diferentes aspectos da diversidade: da relação ambiental, do uso da água, ou de sua ausência como região de seca, ou da importância da vegetação ou do sítio como o de região de lagos. Também pode derivar diretamente das construções humanas: do espaço vivido, do Estado que unifica a nação, da cidade sede do estado imperial, mas também do valor (moeda) e da técnica.

A prática espacial da integração técnica ou tecnificação se desenvolve a partir da ambientalização, territorialização e enraizamento cultural, resultantes da seletividade e da unodiversidade. Inicialmente ligada ao meio geográfico da própria comunidade humana de origem, a técnica, ao desenvolver seu aspecto racional também original, quebra sua relação inicial de pertencimento em detrimento do seu sentido universal e homogêneo.

Desta forma, a seletividade, a unomultidiversidade e a integração técnica, em sua unidade, fundam o problema espacial original da humanidade, uma questão de escolha de localização na multiplicidade ambiental da superfície terrestre, em função das suas condições geográficas e dos problemas e projetos postos por homens e mulheres em cada forma de sociedade ou em um de seus momentos.

Entretanto, este problema espacial não se restringe à localização, aos símbolos de unidade e às técnicas das primeiras civilizações construídas nas encostas montanhosas ou nos vales dos grandes rios, mas também aos atuais processos de seletividade. Exemplos de problemas espaciais são: a escolha da localização da capital do Brasil, a distribuição das Unidades de Polícia Pacificadora (UPPs) na cidade do Rio de Janeiro, a localização de empreendimentos industriais em função da guerra fiscal entre municípios ou estados, a localização de empreendimentos imobiliários em função da especulação da terra urbana, a escolha de terras a ocupar em função da grilagem e da mobilização dos trabalhadores "sem terra", a ocupação das encostas e outras áreas por favelas em função da proximidade do mercado de trabalho, etc..

Os problemas espaciais colocados acima indicam que a seletividade também pode assumir o significado oposto ao seu processo original. Ou seja, na economia de mercado da moderna sociedade de classe, a especialização e fragmentação do arranjo espacial, "em função de uma divisão territorial do trabalho que baixe os custos e aumente a produtividade, no propósito acumulativo capitalista... a seletividade se converte num mecanismo de descarte de espécies... A espacialidade humana assim se desambientaliza, se desterritorializa e se desenraiza inteiramente, numa desespacialidade em que o homem perde por fim sua identidade com o meio" (MOREIRA, 2017, p. 30).

Este desenraizamento corresponde, atualmente, ao processo de globalização. Dissociado do ambiente local em função de seu conteúdo cada vez mais universal, uniforme e tecnificado, o homem é desenraizado territorial e culturalmente, na escala de 
mundo. Este desenraizamento é um processo que se inici(a)ou com a expropriação do campesinato e sua transformação em trabalhador "livre" (proletariado moderno), e que atualmente significa os desligamentos frequentes de sua territorialidade, vida de flutuação e de mobilidade territorial campo-cidade, campo-campo, cidade-cidade e no interior das grandes metrópoles. A metrópole - o moderno processo de urbanização dos meios de vida - é a constituição corpórea desta espacialidade, um meio geográfico impessoal em que as personalidades dos homens e mulheres se fragmentam em múltiplos pedaços espaciais (espaços da moradia, do trabalho, do lazer, do saber, da política, da saúde), fazendo do cotidiano um vai-e-vem permanente (MOREIRA: 1994).

Neste contexto, a unomultidiversidade é marcadamente simbolizada pelo valor (moeda) e pela técnica. Enquanto a moeda unifica o território na construção e na ideologia do Estado-nação, simbolizando a riqueza e o sentido de progresso econômico, a razão técnica atua como prática e como símbolo da unidade do espaço. Daí, então, o autor considerar que a "modernidade se costurou como ideologia e concreticidade justamente nessa cumplicidade do valor e da técnica com o símbolo do imaginário, tornando-a indissociável da suprestrutura simbólica e da infraestrutura material no modo do espaço vivido em que estamos" (MOREIRA, 2017, p. 32).

Da montagem por seletividade e do arranjo espacial a partir da constituição do habitat resultantes das práticas espaciais da unodiversidade, unicidade e tecnificação, o autor desdobra a fase do desenvolvimento através da territorialização, politização, regulação, mobilidade, urbanização, compressão, fluidificação e da sociodensificação.

A técnica e a valoração simbólica do espaço fazem com que distintas comunidades delimitem o seu pedaço na forma de recortes territoriais de domínio, em relação ao contexto espacial mais geral. Já presente nas comunidades em trânsito do nomadismo para o sedentarismo, a territorialização se manifesta mais claramente nas sociedades de classe e de Estado, onde a cidade surge como ponto de comando do seu domínio territorial.

A politização é a ação e a dimensão política do espaço, conformada, então, em territorialidade. Fundamentada num conjunto de contradições já no processo de seletividade, entre unidade e multidiversidade, localização e distribuição, a politização se manifesta nesta relação entre sociedade e espaço em diversas outras contradições: alteridade-centralidade, unidade-diversidade, hegemonia-heterogenia e identidadediferença. Assim, a prática espacial da politização se constitui da "tensão, fruto de o espaço nascer, desde seu cunho de uno-multidiversidade, do signo da contradição" (MOREIRA, 2017, p. 34).

O espaço como regulação da história resulta desta prática espacial de controle daquelas contradições:

\begin{abstract}
A contradição suscita a regulação, relação que vem junto e no espírito do controle sistêmico. Refere-se ao conjunto de regras, normas e princípios de natureza regente do espaço. O veículo é o formato do arranjo - econômico, jurídico, político, cultural, representacional e ideológico - do espaço (Moreira, 2007a), montado a partir do processo da seletividade e por fim ordenado como modo de organização espacial da sociedade. Lacoste designao espacialidade diferencial (Lacoste, 1988). Lefebvre condição de reprodutibilidade (Lefebvre, 1973). Quaini regulação, explicitamente (Quaini, 1979). (Moreira, 2017, p. 35)
\end{abstract}

É assim que a regulação, enquanto norma, atividade codificada, regras de ação e de comportamento, constrangimentos, motivações, tornam o espaço e o território algo normativo, considerando a "preeminência da técnica em todos os aspectos da vida social" (SANTOS, 2004, p. 228-229). Embora gerais e universais, as normas são 
"diversamente eficazes, segundo os lugares, pois o conteúdo técnico e informacional de cada área tem um papel fundamental no comportamento dos agentes" (SANTOS, 2004, p. 230).

A mobilidade de homens e mulheres, jovens e idosos, plantas e animais, produtos e capitais, é a resposta (não a solução, necessariamente) para as tensões, contradições e regulações do espaço. Ampliada pelo grande desenvolvimento técnico dos meios de transporte, a prática espacial da mobilidade se realiza em três modalidades: a urbanização, a compressão e a fluidificação (MOREIRA, 2017, p. $36 / 37)$.

A urbanização é a modalidade de mobilidade que se espalha pelo planeta:

\begin{abstract}
A evolução técnica e dos intercâmbios quebra aqui e ali a tradição, mas não libera a mobilidade migratória para a cidade. Com a capitalização do campo e a aceleração dos meios modernos de circulação que ela promove, os grupos humanos saem em ondas dos territórios aos quais estiveram presos por longo tempo, migram do campo, trocam de lugares com a cidade e mesmo mudam de continente. A população rural abandona o espaço rural em crescendo, alterando os cheios e vazios das velhas arrumações. A urbanização vai assim avançando, primeiro localmente, depois em escala planetária, aumentando o intercâmbio de produtos, mudando hábitos de consumo, dissolvendo antigas culturas. O mundo rural então recua em todos os cantos, em proveito do mundo urbano. O próprio campo com o passar do tempo se torna urbano. (Moreira, 2017, p. 36/37)
\end{abstract}

Por isso, para o autor, como foi indicado mais acima, a metrópole - o moderno processo de urbanização dos meios de vida - é a constituição corpórea da espacialidade do mundo atual.

A modalidade de compressão diminui o sentido físico-planetário do espaço, na medida em que a intensidade das trocas, meios de transferência e novos hábitos de consumo, faz aumentar a velocidade das comunicações e reduzir as distâncias entre os espaços do planeta. O resultado da compressão do espaço é a sua arrumação em rede, tornando-o liso e fluido (fluidificam e redistribuem a localização dos lugares), considerando a eliminação de fronteiras fechadas.

A fluidificação tem o sentido de eliminação das fronteiras, da intensidade dos fluxos e das seletividades fluidas, conseqüência da mobilidade e da compressão: "Retransfigura os arranjos, cujo auge é o ciberespaço. O espaço que, ao fim, se desmaterializa. Se desregionaliza. Dissolve as compartimentações. E valoriza a relação em rede" (Moreira, 2017, p. 38).

A prática espacial da sociodensificação é motor e resultado deste espaço fluido, liso, híbrido e socialmente espesso: "A espessura das relações, fonte do número, que faz da escala a densidade da grade relacional (quanto mais densas as relações, mais absoluta e relativamente denso-tenso é o espaço)" (MOREIRA, 2017, p. 38).

Assim, as práticas espaciais da fase de montagem e de desenvolvimento, estão na base do sucessivo erguimento da estrutura global de arranjo espacial das sociedades.

\title{
Das regiões homogêneas à sociedade organizada em rede
}

$\mathrm{Na}$ fase de reestruturação, se remonta a paisagem por seletividade e, pelas demais práticas espaciais de montagem e desenvolvimento, outro arranjo espacial se estabelece, formando nova relação sociedade-espaço. Moreira (2017, p. 37/38) distingue três épocas de reestruturação, com seus respectivos arranjos espaciais (QUADRO II): 


\begin{tabular}{|c|c|}
\hline \multicolumn{2}{|r|}{ QUADRO II } \\
\hline Épocas & Arranjo Espacial \\
\hline $\begin{array}{l}\text { A fabril da primeira } \\
\text { revolução industrial }\end{array}$ & $\begin{array}{l}\text { É a época do espaço estruturado na } \\
\text { centralidade da fábrica. É o período seletivo- } \\
\text { redistributivo das plantas e animais que as } \\
\text { grandes navegações intercambiam pelos } \\
\text { continentes; do arranjo da sociedade em } \\
\text { regiões homogêneas e relação internacional } \\
\text { centralizada nas grandes praças de mercado } \\
\text { da Europa, o grande espelho dos espaços } \\
\text { coloniais arrumados em sua identidade e } \\
\text { proveito. }\end{array}$ \\
\hline $\begin{array}{l}\text { A fabril da segunda } \\
\text { revolução industrial }\end{array}$ & $\begin{array}{l}\text { É a época da centralidade fabril mundial. } \\
\text { Período da mobilidade técnica da ferrovia, } \\
\text { depois rodovia e navegação aérea, no campo } \\
\text { dos transportes, do telégrafo, depois telefonia, } \\
\text { nas comunicações. E da hierarquia das } \\
\text { regiões polarizadas centrada nas redes de } \\
\text { comando das cidades industriais. }\end{array}$ \\
\hline $\begin{array}{l}\text { A ciberfabril da terceira } \\
\text { revolução industrial }\end{array}$ & $\begin{array}{l}\text { E a terceira é a época atual, de } \\
\text { desterritorialização e dissolução do poder } \\
\text { espacial da indústria, da polaridade do } \\
\text { serviço e da finança rentista, da informação } \\
\text { como matéria-prima e da sociedade em rede. } \\
\text { Dos grandes empórios urbanos de consumo } \\
\text { de massa. }\end{array}$ \\
\hline
\end{tabular}

Sucessivamente, se trata do arranjo espacial das regiões homogêneas, das regiões polarizadas e da sociedade em rede. Em cada um desses momentos, nova era de construção do espaço se estabelece.

\section{O CLÁSSICO COMO CRITÉRIO DE MONTAGEM DE CURRÍCULOS E PROGRAMAS}

Esta exposição de arquétipos, definições, estruturas e formatos do discurso e da prática dos geógrafos, ao longo do tempo, serve ao propósito de definir e atualizar o clássico como critério de seleção de conteúdos e formas de abordagem (conteúdo e método), da montagem de programas e currículos.

A partir da trajetória da questão nuclear - do problema geográfico posto pela história -, de suas matrizes de pensamento e de práticas, estes discursos clássicos foram atualizados em uma nova proposta de construção do raciocínio geográfico-espacial e de escolha e organização de conteúdos da pesquisa e do ensino de geografia. A partir de uma teoria social do espaço, Moreira (2010b, 2017) propôs que a geografia seja compreendida como uma ciência das práticas e dos saberes espaciais.

Neste fim cabe retomar o clássico como critério de definição de programas e currículos, a partir de tudo que foi apresentado.

Embora Saviani $(2010,27 / 28)$ se refira à pedagogia, os aspectos que destaca para definir a importância do "clássico", cabem às demais disciplinas escolares:

a) Fornece critério para distinguir o principal do secundário, o duradouro do efêmero; o que indica tendências estruturais do que se reduz à esfera conjuntural. 
b) Fornece os grandes autores, textos e temas que condensam grandes possibilidades de formação sólida e realização do trabalho pedagógico.

c) Fornece critério de montagem de currículos, ao distinguir atividades nucleares da escola das atividades extracurriculares, auxiliares do processo formativo.

d) Fornece referência à organização da educação em seu conjunto, seus níveis e modalidades articulados no espaço e no tempo.

Para este autor, o papel da escola "é o acesso ao saber elaborado, que se expressa por escrito....referência clássica para a organização do currículo escolar" (SAVIANI: 2010, p. 27). Desta forma:

\begin{abstract}
...o componente clássico elementar do currículo escolar é a língua materna ...em sua codificação escrita; os outros componentes são: a matemática, ou linguagem dos números; as ciências da natureza, que no ensino fundamental assumem a forma de "ciências naturais" e no ensino médio se constituem nas disciplinas de biologia, física e química; e as ciências da sociedade, tratadas no ensino fundamental, como história e geografia, às quais se acrescentam no ensino médio, filosofia, sociologia e psicologia, podendo, em determinadas circunstâncias, sofrer novos desdobramentos, contemplando-se outras disciplinas como antropologia e economia. Se considerarmos, além desse aspecto que se refere à educação intelectual, o aspecto do desenvolvimento corporal e emocional, o currículo propriamente dito em sua referência clássica envolveria, além dos mencionados estudos da língua escrita, da matemática e das ciências da natureza e da sociedade, a educação física e a educação artística. (Saviani, 2010, p. 27/28)
\end{abstract}

Esta finalidade da escola é a base para a elaboração dos métodos e formas para atingi-la, seguindo a interpretação de Gramsci, segundo o qual é "nos fins a atingir" que deve ser buscado "a fonte natural para elaborar os métodos e as formas" (GRAMSCI, s/d, p. 115; SAVIANI, 2010, p. 27).

Quanto ao que é principal no ensino de geografia, é possível propor:

1. Tomar o caráter de classe e de luta do modo de vida, da constituição do habitat e da geografia do presente momento histórico como conteúdo inspirador de conceitos e métodos que permitam seu questionamento, investigação e ensino; e ponto de partida e de chegada do desenvolvimento de todo e qualquer conteúdo.

2. O uso das categorias empíricas das práticas espaciais ${ }^{19}$ e das categorias teóricas da paisagem, do território e do espaço, de forma a conformar nos alunos o raciocínio geográfico-espacial; a partir do desenvolvimento de todo e qualquer conteúdo.

3. Que permita remontar intelectualmente as distintas formas e fases da organização geográfica das sociedades ao longo da história; desde as primeiras formas de sociedade, passando pelas fases de montagem do arranjo espacial a partir da expansão da cultura ocidental, até as três épocas de reestruturação do espaço geográfico do capitalismo a partir do período técnico fabril.

4. O movimento das práticas espaciais à consciência geográfica e ao raciocínio geográfico-espacial (e vice-versa), que permita visualizar a apreensão dos fenômenos naturais em função da prática social no arranjo espacial (concepção unitária da geografia) e em suas distintas escalas de análise (LACOSTE, 2010).

Quanto aos autores clássicos, George Tatham e Ruy Moreira fazem referências à Estrabão e Ptolomeu do mundo antigo (gregos, séc. I e II), Bernard Varenius (alemão, séc. XVII), os Forters e Imannuel Kant (alemães, séc. XVIII), Karl Ritter e Alexander Von Humboldt (alemães, primeira metade do séc. XIX), que influenciaram a geografia 
escolar brasileira. No final do século XIX e início do século XX vão se constituir as geografias sistemáticas ${ }^{20}$ - com seus respectivos fundadores -, a geografia humana (Ratzel, Brunhes) e a geografia física (De Martonne), e a geografia regional (Hettner, La Blache). As fundações da geografia universitária e do IBGE na década de 1930 resultam de quatro influências: a francesa de La Blache, a franco-germânica de Brunhes, a germânica de Hettner e a norte-americana de Sauer e Richard Hartshorne (1899-1992); trazidos para o Brasil por Pierre Monbeig (1908-1987) e Francis Ruellan (1894-1975), Pierre Deffontaines (1894-1978), Leo Heinrich Waibel (1888-1951) ${ }^{21}$. Perspectivas, linguagens e epistemologias que marcarão as geografias do século XX e até os dias de hoje.

Quanto à montagem de currículos e à organização dos níveis de ensino e da relação espaço-tempo, é possível propor:

1. A presença da geografia como componente curricular na escola básica; podendo ser articulada com o ensino de história nos primeiros cinco anos do ensino fundamental; mas de forma independente nos demais anos.

2. Uma determinada distribuição dos conteúdos por níveis de ensino, uma sugestão para debate, que segue (QUADRO III):

\begin{tabular}{|c|c|}
\hline \multicolumn{2}{|r|}{ QUADRO III } \\
\hline $\begin{array}{c}\text { Níveis de } \\
\text { ensino }\end{array}$ & Conteúdos propostos \\
\hline $1^{\circ}$ ao $5^{\circ}$ ano & $\begin{array}{c}\text { As fases de montagem e desenvolvimento do arranjo } \\
\text { espacial das diferentes sociedades } \\
\text { Privilegiar a articulação da escala local com a escala } \\
\text { nacional-regional }\end{array}$ \\
\hline $6^{\circ}$ ao $9^{\circ}$ ano & $\begin{array}{l}\text { Montagem, desenvolvimento e reestruturação espacial } \\
\text { 1. As fases de montagem e desenvolvimento do arranjo } \\
\text { espacial das diferentes sociedades } \\
\text { 2. Montagem e desenvolvimento do arranjo espacial da } \\
\text { sociedade burguesa } \\
\text { 3. Montagem e desenvolvimento do arranjo espacial } \\
\text { capitalista na construção do Brasil } \\
\text { 4. As três épocas de reestruturação espacial da sociedade } \\
\text { burguesa } \\
\text { Articular as escalas locais, nacionais-regionais e } \\
\text { mundiais-regionais }\end{array}$ \\
\hline Ensino médio & $\begin{array}{l}\text { As três épocas de reestruturação espacial da } \\
\text { sociedade burguesa } \\
\text { 1. A fabril da primeira revolução industrial } \\
\text { 2. A fabril da segunda revolução industrial } \\
\text { 3. A cibernética da terceira revolução industrial } \\
\text { Privilegiar a articulação das escalas nacionais- } \\
\text { regionais e mundiais-regionais }\end{array}$ \\
\hline
\end{tabular}

Esta distribuição de conteúdo, combinada com a metodologia da articulação das práticas/saberes espaciais dos alunos com os conteúdos escolares, faz da escala nacional-regional, ou seja, do Brasil, um tema presente nos três níveis de ensino delimitados. Para preencher de conteúdos cada fase de constituição geográfica das sociedades e, conseqüentemente, dos níveis de ensino, propõe-se como ponto de partida a delimitação dos principais problemas e desafios do Brasil e da sociedade brasileira. 
Resultantes das características centrais do arranjo e da produção do espaço capitalista e produto das práticas espaciais de sujeitos hegemônicos e contra-hegemônicos, tais problemas constituem os conteúdos fundamentais a partir dos quais as propostas curriculares devem ser construídas.

Por fim, o "clássico", como apresentado acima, também serve de critério para organizar aulas, delimitar o conteúdo de uma prova, avaliar criticamente e produzir materiais e livros didáticos; tendo como referências a prática social e sua apropriação dos fenômenos naturais na geografia do presente, o uso dos conceitos geográficos, a reconstituição intelectual das distintas formas de organização geográfica das sociedades em diferentes escalas.

\section{NOTAS}

1 - Manoel Correia de Andrade (1987, p. 22, 23) adverte que os gregos utilizaram os conhecimentos empíricos da Geografia acumulados pelos povos orientais.

2 - MOREIRA (2014, p. 81), apoiando-se em Nelson Werneck Sodré e Horacio Capel, afirma: "Uma diferença substantiva distingue, todavia, a Geografia moderna e a Geografia antiga... a presença essencial das instituições na determinação do seu lugar, papel e formato de ciência, Trata-se do papel das Sociedades de Geografia, do ensino escolar e dos departamentos universitários".

3 - Física, no sentido grego, significava o conjunto das coisas que existem, orgânicas e inorgânicas; o que há ao redor e que é visto e sentido. Desta forma, a filosofia natural descrevia e explicava o mundo em sua totalidade.

4 - Hartshorne (1978, p. 72) afirma que o termo "Geografia Física", já presente na época de Varenius, correspondia à sua geografia geral ou sistemática, mas que incluía o estudo dos fenômenos da vida e da natureza inanimada, da natureza incluindo o homem.

5 - Tatham expõe o texto de Kant "Introdução às suas aulas de geografia física", ministradas por 40 anos, no período de 1756 a 1796 na Universidade de Koenigsberg, Alemanhã.

6 - O que não corresponde ao conceito atual de geografia física.

7 - As citações de Ritter, utilizadas por Tatham, foram retiradas da obra do geógrafo alemão E. Plewe.

8 - Holanda, Bélgica, Inglaterra, França, Venezuela, Cuba, Equador, Peru, Estados Unidos, etc.

9 - Geomorfologia, climatologia, biogeografia, geografia urbana, geografia industrial, geografia agrária, etc.

10 - "Ratzel, dominado, ao mesmo tempo, pelo seu preconceito de antropogeógrafo e por preocupações de ordem mais política que científica, que, por momentos, nos faz comparar a mais recente e menos fecunda das suas grandes obras, a Politische Geographie, a uma espécie de manual do imperialismo alemão" (Febvre, 1954, p. 445-446).

11 - De acordo com Ruy Moreira (2008, p. 38-43), Lucien Febvre foi o criador da ideia simplista e equivocada de escola nacional alemã de geografia (determinista) e escola nacional francesa de geografia (possibilista), apoiadas respectivamente em Ratzel e La Blache. Lucien Febvre afirma de forma pouco precisa e despretensiosa esta classificação: "Ora não entremos, por agora, na pormenorização das doutrinas. Não perguntemos se, no conjunto das ideias geográficas, não há realmente fendas e se se podem seguir simultaneamente, com a mesma calma segurança, os "deterministas" à maneira de RATZEL e os que poderíamos talvez chamar os "possibilistas" à maneira de VIDAL DE LA BLACHE" (Febvre, 1954, p. 429 30).

12 - No ítem VI - Uma geografia humana modesta - do capítulo 1 - MORFOLOGIA SOCIAL OU GEOGRAFIA HUMANA.

13 - “O solo, não o Estado: eis o que deve preocupar o geógrafo” (Febvre, 1954, p. 465). 
14 - De acordo com Tatham (1959, p. 223) a "influência da biologia evolucionista levou Ratzel a adotar a teoria orgânica do estado e sociedade, isto é, o conceito do estado como um organismo, parte humano e parte terrestre". Embora, em edição posterior Ratzel tenha revisto esta tese do Estado-organismo.

15 - Iniciada com Fred kurt Schaefer (1904-1953), com o texto publicado em 1953 nos Anais da Associação de Geógrafos Americanos; e no Boletim Carioca de Geografia da AGB-Rio em 1976, com o título "O excepcionalismo na Geografia: um estudo metodológico".

16 - Pierre George (1909-2006), organizador (junto com Raymond Guglielmo, Bernard Kayser e Yves Lacoste) e autor do capítulo introdutório do livro “A Geografia Ativa” de 1964.

17 - Jurandy Ross (2006) debate a análise geográfica integrada a partir da retrospectiva do conceito de Geossistemas de Sotchava, passando por sua versão germano-francesa através das obras de Bertrand, Troll e Tricart, a partir das quais o conceito de geossistemas chega ao Brasil.

18 - Moreira (2017, p. 29) indica que, neste processo, os homens criam “áreas laboratórios (La Blache), antes de se sedentarizar".

19 - A Seletividade, a Unodiversidade, a Unicidade, a Tecnificação, a Politização, a Regulação, a Mobilidade, a Urbanização, a Compressão, a Fluidificação, a Sociodensificação e a Reestruturação.

20 - Geomorfologia, climatologia, biogeografia, geografia econômica, geografia urbana, geografia industrial, geografia agrária, etc.

21 - Será necessário incluir o estudo sistemático dos autores brasileiros: Fernando Raja Gabaglia, Honório Silvestre, Delgado de Carvalho, Everardo Backheuser, Fabio de Macedo Soares Guimarães, Jorge Zarur, Alberto Ribeiro Lamego, José Veríssimo da Costa Pereira, Aroldo de Azevedo, entre outros; e ainda os autores mais contemporâneos.

\section{REFERÊNCIAS BIBLIOGRÁFICAS}

ANDRADE, M. C. de (1987). Geografia, ciência da sociedade: uma introdução à análise do pensamento geográfico. São Paulo: Atlas.

COLESANTI, M. T. M. (1984). O ensino da geografia através do livro didático no período de 1890 a 1971. Rio Claro-SP: Programa de Pós-Graduação em Geografia do Instituto de Ciências Exatas-UNESP, dissertação de mestrado.

COUTO, M. A. C (2011). Método dialético na didática da geografia. In CAVANCANTI, L. S.; BUENO, M. A.; SOUZA, V. C. - org. Produção do conhecimento e pesquisa no ensino da geografia. Goiânia: Ed. da PUC Goiás.

FEBVRE, L. e BATAILLON, L. (1954). A Terra e a evolução humana - introdução geográfica a história. In Panorama da Geografia - volume II, livro III - Geografia Humana. Lisboa: Edições Cosmos.

FONSECA, J. B. V. da (1956). O ensino da geografia no Brasil. Rio de Janeiro: Instituto Pan-Americano de Geografia e História (Comissão de Geografia).

GRAMSCI, A. (s/d). Os intelectuais e a organização da cultura. São Paulo: Círculo do Livro S.A/Ed. Civilização Brasileira.; tradução de Carlos Nelson Coutinho.

HARTSHORNE, R. (1978). Propósitos e natureza da geografía. São Paulo: Hucite/Edusp.

LA BLACHE, P. V. de (1985). As características próprias da geografia. In CHRISTOFOLETTI, Antonio - organizador (1985). Perspectivas da Geografia. São Paulo: DIFEL, p. 37-47.

LACOSTE, Y. (2010). A Geografia - Isso Serve, Em Primeiro Lugar, Para Fazer a Guerra. Papirus Ed.: S.Paulo-SP.

MACHADO, R. (1981). Ciência e saber: a trajetória da arqueologia de Michel Foucault. Rio de Janeiro: Edições Graal. 
MARX, K. (2011). Grundrisse - manuscritos econômicos de 1857-1858, esboços da crítica da economia política. São Paulo: Boitempo; Rio de Janeiro: Ed. UFRJ.

(1989). Manuscritos económicos-filosóficos. Lisboa-Portugal: Edições 70.

MARX, K. e ENGELS, F. (2007). A ideologia alemã: crítica da mais recente filosofia alemã em seus representantes Feuerbach, B. Bauer e Stirner, e do socialismo alemão em seus diferentes profetas (1845-1846). São Paulo: Boitempo.

MOREIRA, R. (1987). O discurso do avesso - para a crítica da geografia que se ensina. Rio de Janeiro: Ed. Dois Pontos.

(1994). Espaço, corpo do tempo - a construção geográfica das sociedades.

São Paulo: DGeo da FFCL da USP (Tese, doutorado em Geografia Humana).

(2006). Para onde vai o pensamento geográfico? Por uma epistemologia

crítica. São Paulo: Editora Contexto.

(2007). Pensar e ser em geografia. São Paulo: Contexto.

(2008). O pensamento geográfico brasileiro. São Paulo: Contexto; volume

1: as matrizes clássicas originais.

(2009). O pensamento geográfico brasileiro. São Paulo: Contexto; volume

2: as matrizes da renovação.

(2010). O pensamento geográfico brasileiro. São Paulo: Contexto; volume

3: as matrizes brasileiras.

(2010b). O que é geografia. São Paulo: Brasiliense. $2^{a}$ edição.

(2014). O discurso do avesso - para a crítica da geografia que se ensina.

São Paulo: Contexto.

(2017). Uma ciência das práticas e saberes espaciais. São Gonçalo-RJ:

Revista Tamoios, XXXXX.

PRADO JUNIOR, C. (1945). Introdução. In CASAL, Aires de. Corografia Brasílica. Rio de Janeiro: Imprensa Nacional. Ministério da Educação e Saúde/Instituto Nacional do Livro, Coleção Obras Raras, tomo II.

ROSS, J. (2006). Ecogeografia do Brasil - subsídios para planejamento ambiental. São Paulo: Oficina de Textos.

SANTOS, M. (2004). A Natureza do Espaço: Técnica e Tempo, Razão e Emoção. São Paulo: Editora da Universidade de São Paulo; $4^{\mathrm{a}}$ ed. 1.reimpr. (Col. Milton Santos; 1).

SAVIANI, D. (2007). História das ideias pedagógicas no Brasil. São Paulo: Editora Autores Associados, 472 p.

(2010). Importância do conceito de "clássico" para a pedagogia. In

TEIXEIRA JR, Aguinaldo - org. Marx está vivo! Maceió: Agência Curso Comunicação e desenvolvimento; pg. 15-28.

(2014). Sistema Nacional de Educação e Plano Nacional de Educação: significado, controvérsias e perspectivas. Campinas, SP: Autores Associados.

STRABON (1880). Géographie. Paris: Librairie Hachette ET Cie; traduction nouvelle par Amédée Tardiei; tome troisième, livre XIII à XVII.

TATHAM, G. (1959). A geografia no século dezenove. Rio de Janeiro: IBGE, Boletim Geográfico; n 150, ano XVII, maio-junho; p. 198-226. 